\title{
Pasado y presente de la Arqueología Subacuática en Cantabria
}

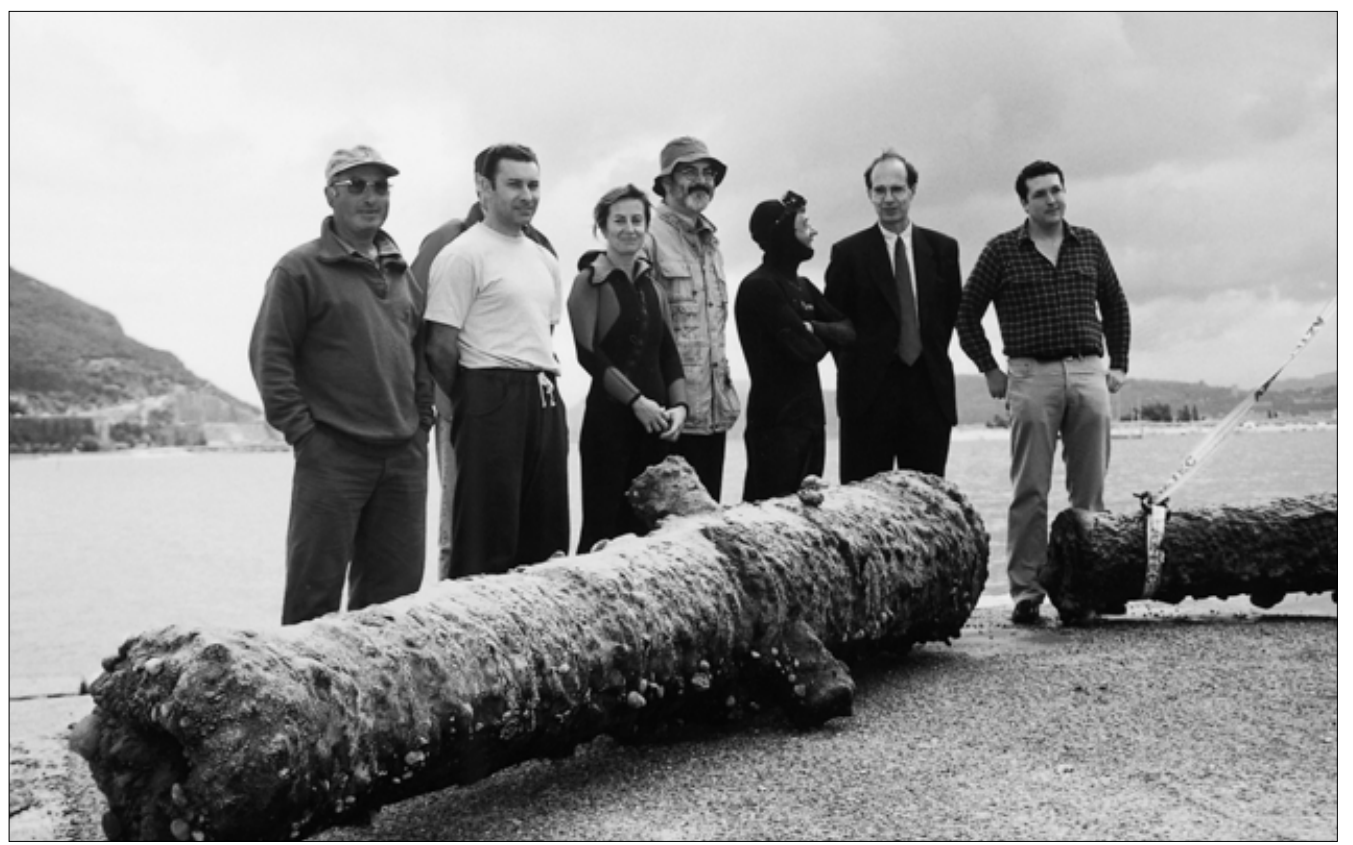

Equipo de Arqueología Subacuática del Museo Marítimo. A la derecha el Consejero de Cultura y el Concejal de Cultura del Ayuntamiento de Santoña. Todos posando junto al rescate de los cañones que habían sido tirados al agua, desde el fuerte de San Carlos.

\section{Belén Gómez Vega}

Arqueóloga Subacuática

Directora de los Cursos de Buceo

Profesional/Arqueología Subacuática de la Escuela Náutico-Pesquera de Santander

La importancia histórica de la costa de Cantabria está determinada por las excepcionales condiciones de abrigo de sus bahías más importantes, Santander, Santoña, Laredo, San Vicente de la Barquera y Castro Urdiales. Durante siglos, han sido utilizadas como lugar de resguardo de temporales y como base para la formación de armadas. Reflejo de ese pasado comercial y militar, es la gran cantidad de objetos arqueológicos que, tanto furtivamente, como de forma casual se han extraído de sus aguas, destacando sobre cualquier otro, los cañones.
En este sentido, uno de los hechos más significativos fue la aparición de los restos de un barco durante las obras de reconstrucción de la Catedral de Santander, tras el incendio que destruyó la ciudad en 1941. Conservaba la quilla con trozos de cuadernas y tablazón, ensamblado con la técnica romana de mortajas y lengüetas fijadas con cabillas de madera. El descubrimiento tubo lugar en la ría de Becedo que, antes de su relleno, pasaba por debajo del cerro de Somorrostro, sede de la Catedral.

Así mismo, en las excavaciones arqueológicas iniciadas en 1983 en la iglesia baja de aquella y posteriormente en su claustro, se encontraron estructuras romanas. Tales restos parecen confirmar que el primitivo puerto de Santander, y según se desprende el puerto romano que citan las fuentes "Portus Victoriae luliobriguensis", estaba situado en la citada ría, debajo del cerro donde posteriormente se construyó el conjunto catedralicio. En este caso no hubo lu- 
gar para la realización de una excavación, puesto que la ría de Becedo se rellenó a finales del siglo pasado y hoy día es uno de los centros neurálgicos de la ciudad, pero contradijo la hipótesis tradicional que situaba dicho puerto en la ensenada de la Magdalena.

El estudio de tales acontecimientos concluyó en la necesidad de realizar la Carta Arqueológica Subacuática de Cantabria, con el objeto de localizar posibles pecios y estructuras portuarias y prevenir posibles destrozos del patrimonio cultural subacuático de la zona.

La primera intervención propiamente dicha tubo lugar en 1986 y 87 en San Vicente de la Barquera y fue dirigida por J.L. Casado Soto y por M. Martín Bueno, responsables del Laboratorio para Investigaciones Arqueológicas Submarinas (L.I.A.S.) y de la Cátedra de Arqueología de la Universidad de Zaragoza.

Al realizarse las obras de ampliación de la calzada del puente del Peral, situado en la entrada del puerto, las corrientes excavaron dos grandes pozos a ambos lados de sus pilares, descubriéndose el antiguo fondeadero de San Vicente, de uno de los cuatro puertos aforados de la región.

Según los responsables de la intervención, la abundancia del material acumulado en los pozos y las corrientes en ese lugar, determinaron el sistema de trabajo utilizado, que consistió en la recuperación de cas 2.000 fragmentos cerámicos, que han permitido establecer más de ochocientas formas diferentes datables entre los siglos XIII al XIX. Entre los dos equipos calculan haber rastreado casi $20.000 \mathrm{~m}^{2}$ de fondo.

En Cantabria no se volverían ha llevar a cabo proyectos arqueológicos subacuáticos hasta 1990, a excepción de algunas intervenciones puntuales por parte del Museo Marítimo. Durante ese año, y con motivo del dragado de la Canal del Puerto de Santander, se firmó un Convenio de colaboración entre la Consejería de Cultura, el Puerto, la Sociedad Estatal Quinto Centenario y la Universidad. Los objetivos propuestos fueron, el realizar una prospección integral de la citada canal, y al mismo tiempo consolidar el equipo de arqueología subacuática que se estaba formando. La sede de las operaciones se centralizó en el Museo
Marítimo del Cantábrico y la dirección arqueológica estuvo a cargo de su director J.L. Casado Soto.

En colaboración con la empresa Intecsa se realizó una prospección geofísica completa de la Canal de la bahía, en la que se detectaron varias anomalías arqueológicamente interesantes, que fueron comprobadas por arqueólogos subacuáticos mediante prospecciones circulares y detector de metales. El resultado fue la constatación de lo que podían ser varias estructuras de pecios, enterradas entre uno y cuatro metros de arena, y en 16/22 metros de agua. Sin embargo no se llevó a cabo ninguna excavación arqueológica, por lo que no se pudo determinar su cronología.

Por otro lado, la abundante información que nos llegaba sobre la extracción de objetos por parte de furtivos en aguas de la bahía de Santoña-Laredo, hizo que durante ese mismo año de 1990, el equipo del Museo Marítimo, centrara sus trabajos en el estudio de los posibles yacimientos arqueológicos enterrados en dicha bahía.

En las prospecciones realizadas en 1996 se descubrió un total de 12 pecios, algunos con peligro de desaparición por causa de las malas mares, de su accesibilidad y de los furtivos, debido a lo cual, consideramos dicha bahía como "un yacimiento" de alto valor para el Patrimonio arqueológico.

La campaña estuvo dirigida por José L. Casado Soto y fue realizada por la arqueóloga que firma este artículo y dos buzos profesionales. El trabajo se centró en posicionar cada uno, dibujar la estructura que conservaban con la toma de todo tipo de medidas y finalmente fotografiarlos, encargo que se hizo a Jaime Maruri. Estudiado el panorama, se comprobó que de todos ellos, había dos de especial interés debido a la cantidad de estructura de madera que conservaban y a la importancia de su arquitectura naval. Finalmente, el director del proyecto decidió centrar los esfuerzos en uno de ellos ante el peligro de su desaparición, ya que se encuentra en el canal de paso de los pesqueros al puerto de Santoña, el Ilamado "Pecio de La Almiranta".

En las campañas arqueológicas siguientes se pudo comprobar que se trataba de un pecio importante, debido al porte de los maderos de su estructura, así como al tamaño de los dos cañones encontrados, de poco más de 3 metros.

Desde entonces, se han realizado varias campañas arqueológicas sistemáticas centradas en la toma de medidas, el dibujo y la fotografía, que han permitido plantear una primera topografía, y determinar así la importancia del yacimiento.

En el momento actual de las investigaciones, podemos confirmar que se trata del galeón "Nuestra Señora de la Concepción", nave Almiranta de la Escuadra de Galicia, que fue incendiada y hundida por su tripulación durante la batalla que tuvo lugar en esa bahía contra los franceses en 1639, durante la última fase de la Guerra de los 30 Años. 
Sus restos los hemos localizado a unos 70 metros al oeste de la plaza de toros de Santoña, a una profundidad entre 6 y II metros.

La importancia de su descubrimiento estriba fundamentalmente en que, un galeón de esa época estaba en la vanguardia de la tecnología de la construcción naval en el mundo, y en el hecho de que se trata del primero encontrado con buena parte de su estructura de madera bien conservada, aproximadamente 30 $\times 8$ metros.

En la actualidad se encuentra pendiente de realizar una excavación arqueológica, mientras esto sucede, se ha cubierto el yacimiento con sacos de arena para su total protección, está en la zona de paso de los pesqueros.

Otro pecio importante localizado durante la campaña de prospección antes referida, es el llamado "Pecio del Doncel". Situado en la bocana del puerto, entre Santoña y Laredo, fue expoliado en los años sesenta (se llevaron casi toda su carga formada por cañones deteriorados para fundición) y ha sido objeto de excavación hasta el presente año por parte de un equipo de buceadores dirigidos por Baldomero Brígido. Desde el primer momento, la intervención se basó en la extracción sistemática de los cañones que quedaban, utilizando para ello un detector de metales.

En la actualidad, la metodología llevada a cabo en este yacimiento ha estado en proceso de revisión por parte de los organismos competentes de la Consejería de Cultura. Como resultado se ha producido un cambio de orientación en la dirección del proyecto.

Por otro lado, la creciente flota pesquera de Santoña propició la reestructuración de su puerto, lo que dio lugar a la construcción en 1998 del "Nuevo muelle pesquero en la dársena sur del puerto de Santoña".

Al inicio de la obra, el Servicio de Patrimonio Cultural informó de la necesidad de realizar un seguimiento arqueológico del dragado, en consideración a la importancia arqueológica del lugar. De este modo, y en coordinación con la Dirección General de Puertos (titular del proyecto), me propusieron llevarlo a cabo.

El seguimiento tenía como objetivo el control arqueológico de las obras, con el fin de garantizar la correcta gestión del patrimonio, pues se trataba de una zona de alto riesgo desde el punto de vista arqueológico. Debido a sus características, el tipo de técnica utilizada fue la prospección visual, si bien se buceó en las zonas más comprometidas para realizar comprobaciones.

El dragado se realizó sin novedad, salvo la variedad de objetos diversos que salían; el fondo era fangoso y a veces mezclado con restos de artes de pesca. Sin embargo, cuando se estaba llegando a la cota - 3 en el área interior de la dársena antigua, "la cuchara" extrajo un objeto de grandes proporciones, que se dejó en la pontona para su observación. A los pocos minutos se personó la Guardia Civil del Mar alarmados por el ta- maño del objeto. Comprobamos que se trataba de un objeto de madera hecho en una pieza, que fue extraído del árbol siguiendo su veta y después trabajada en parte de sus laterales y extremos para que encajara con algo (quizá otras piezas). Por otro lado, tiene una zona visiblemente atacada por el "teredo", incluso pueden verse las galerías calcáreas que deja el animal.

Estas consideraciones, su forma, tamaño y peso $(2,38$ m. x I,68 m. y unos $400 \mathrm{~kg}$.) me llevaron a creer que se trataba de una pieza arqueológica importante, posiblemente encuadrada en la construcción naval de época moderna. Respecto a su uso, en una primera observación, tan sólo se pueden establecer hipótesis: aunque tiene el aspecto de un codaste de época moderna, su terminación "afilada" inclina a suponer que se trata de una pieza que posiblemente formaba parte de un muelle de madera (a juzgar por los paralelos encontrados en los muelles de madera ingleses). Posteriormente, la documentación consultada corroboró que cerca de esa zona se localizaba el antiguo muelle de madera de Santoña.

La pieza se fotografió y dibujó con sus dimensiones, después se la envolvió con telas empapadas de agua, advirtiendo que debían permanecer así continuamente para evitar un secado descontrolado. Inmediatamente se informó a las autoridades, decidiéndose su traslado a un almacén municipal hasta que la Consejería de Cultura determinara el método de conservación más eficaz y una ubicación definitiva. En este sentido, solicité información al especialista en madera empapada en agua del C.N.I.A.S., quien nos recomendó un tratamiento preventivo y de urgencia.

En la actualidad, las intervenciones arqueológicas subacuáticas en Cantabria continúan centrándose en la bahía de Santoña-Laredo. Prueba de ello son los dos únicos permisos de actuaciones arqueológicas solicitados y concedidos en la campaña de este año: uno para la excavación del "Pecio del Doncel", dirigido

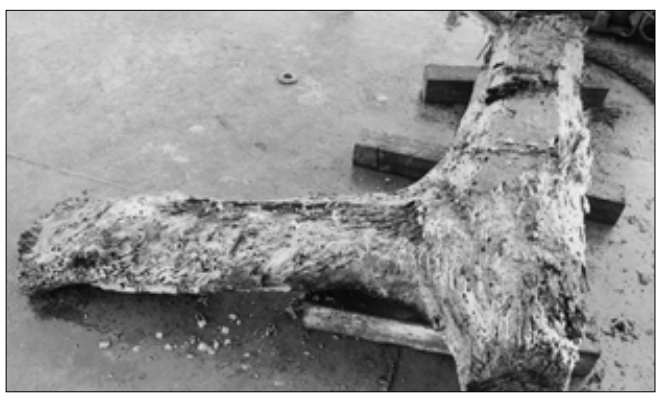

Objeto procedente del dragado, que puede ser parte del antiguo muelle de madera de Santoña.

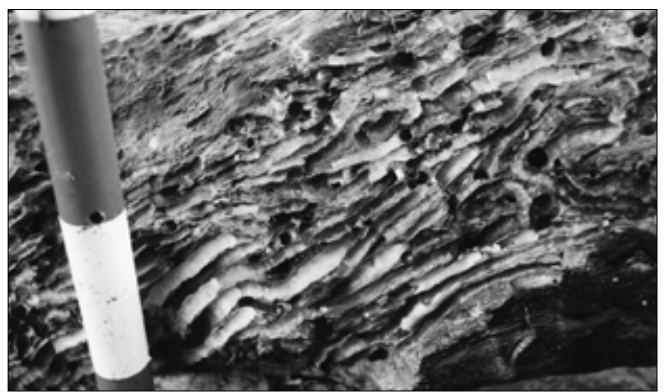

Detalle de las galerías excavadas por el "teredo" en la pieza de madera. 


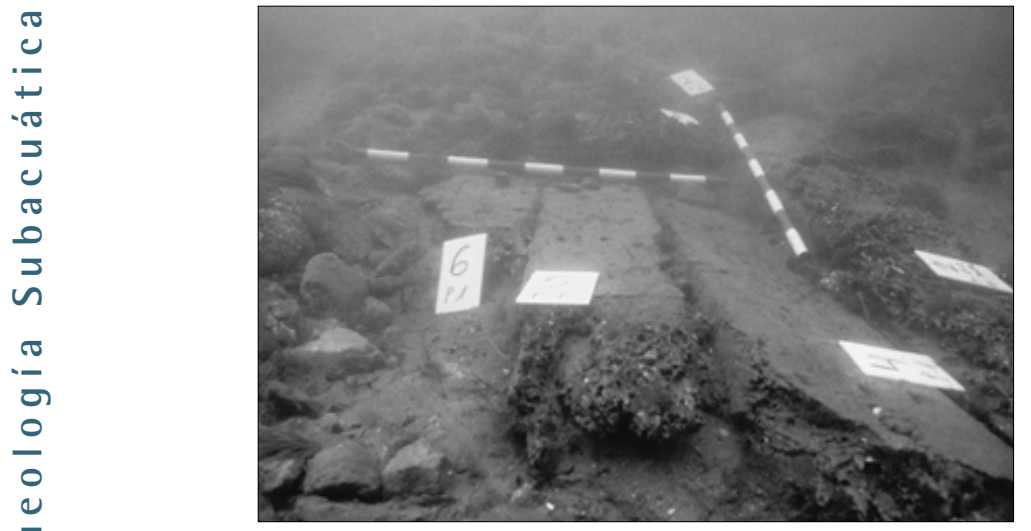

은

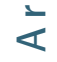
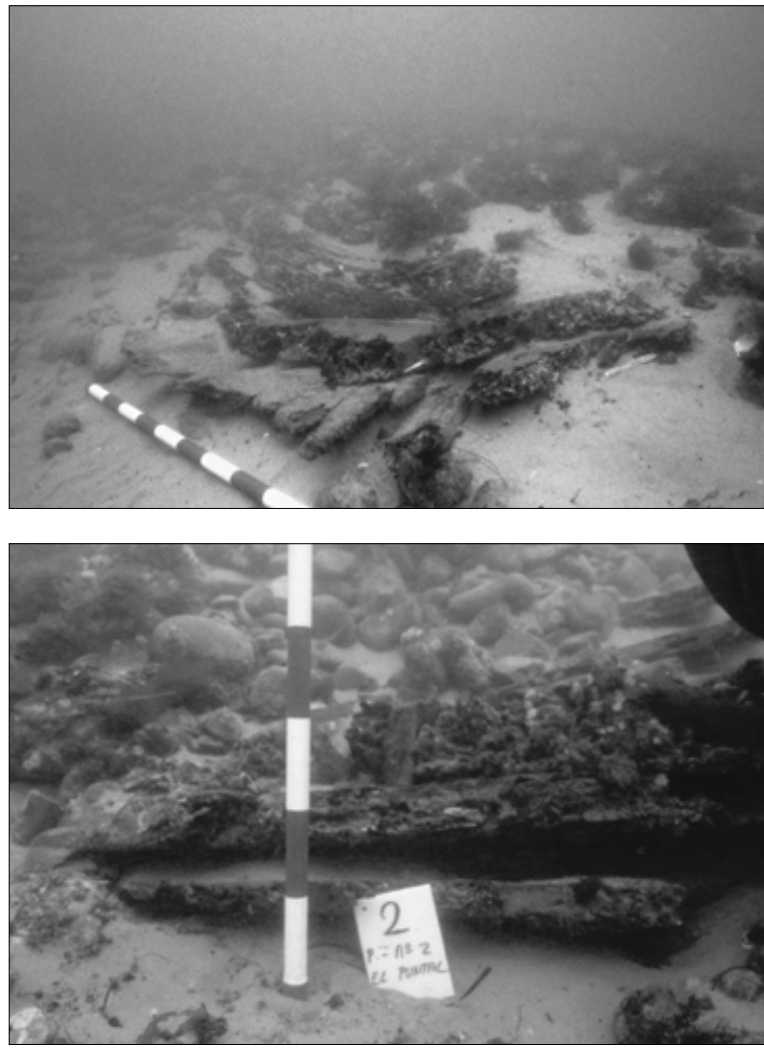

Detalle del "Pecio de el Puntal", descubierto en las prospecciones de 1996 por el equipo del M.M.C.

Panorámica de una parte del "Pecio de El Puntal"

Detalle del forro del "Pecio de La Almiranta" por B. Brígido y en el presente en vías de revisión, y el otro para la prospección del "Pecio de San Carlos", que incluía la inspección de la cubrición del "Pecio de La Almiranta" y la recuperación de dos cañones del fuerte de San Carlos (que habían sido arrojados al mar), todo ello dirigido por J.L. Casado Soto

El "Pecio de San Carlos", Ilamado así por encontrarse debajo del fuerte del mismo nombre y a unos cuarenta metros de la costa, se descubrió durante las prospecciones realizadas por este mismo equipo en 1996, año en el que apareció semi enterrado por la arena un cañón con abundante munición. En la campaña actual se trató de delimitar su importancia y valor documental, así como definir si se trataba de un pecio o de dos. En las primeras intervenciones comprobamos que las mareas habían introducido mucha arena, por tanto la prospección se realizó a base de radiales visuales, utilizando el detector de metales. Los resultados están en vías de estudio.
Como se puede observar, el panorama de la arqueología subacuática en Cantabria se circunscribe a las actuaciones de estos dos grupos, que han centrado sus investigaciones en aguas de Santoña. Sin embargo, nos llegan noticias sobre la aparición de restos arqueológicos sumergidos en otros puertos o bahías, como en la de Santander o Castro Urdiales, por citar las más destacables, que no pueden comprobarse por falta de medios y de arqueólogos formados en la especialidad subacuática.

En este sentido, y con el propósito de paliar la deficiencia de formación, la Escuela Náutico-Pesquera de Santander por medio de su director D. Julio González Vega, en coordinación con quién suscribe, decidió dar respuesta a esta demanda creando un curso profesional de buceo adecuado a nuestra profesión. Así, en 1996 iniciamos el I Curso de Arqueología Subacuática /Buceo Profesional, que se viene impartiendo desde entonces durante los meses de septiembre en la E. N-P.

El curso pretende proporcionar a licenciados en Historia y restauradores, una especialización en arqueología subacuática en dos sentidos. Por un lado, impartiendo un Curso de Buceo Profesional (por parte de la Sección de Actividades Subacuáticas de la Escuela) y por otro, realizando un Curso de Arqueología Subacuática en el que se imparten clases teórico-prácticas sobre todos los aspectos metodológicos relacionados con el tema, incluyendo el legislativo, el cual está a mi cargo. Al finalizar el curso, de un mes de duración, los alumnos que lo superen obtendrán ambas titulaciones.

Durante el III y IV Curso (1998-99) solicitamos de la Consejería de Cultura, permiso para realizar una prospección real con los alumnos, en una zona concreta de la bahía de Santander, que se enmarcó dentro de las prácticas relacionadas con los distintos métodos de prospección utilizados en arqueología subacuática.

Desde el punto de vista metodológico, las prácticas fueron muy positivas, pero en cuanto al aspecto arqueológico, el resultado estuvo condicionado por la colmatación de arena en esta parte de la bahía. No obstante, creemos que la zona propuesta es interesante, sin riesgo para los alumnos, y dados los buenos resultados del último año, estamos considerando repetir la experiencia.

Este es el panorama de la arqueología subacuática en Cantabria. En cuanto a la parte institucional hay que destacar que, en la actualidad, todavía no existe un Centro de Arqueología Subacuática, así como tampoco un arqueólogo territorial con esta especialidad. Sin embargo, las perspectivas son buenas y esperamos que el panorama mejore, dada la importancia de los yacimientos descubiertos recientemente en este campo. 